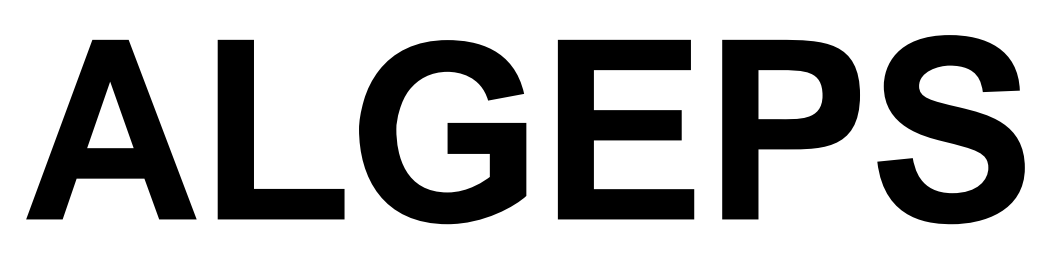

REVISTA DE GEOLOGIA, SĖRIE B no 579 - Gener del 2012

ISSN $1132-7014$

D.L.B. 28.178 - 92

11 pàgines

\begin{abstract}
RECORRIDO DESDE AZUARA A LETUX, ALMONACID DE LA CUBA, BELCHITE Y AL PLANERÓN, A TRAVÉS DEL PATRIMONIO GEOLÓGICO Y MINERO DE LAS COMARCA DEL CAMPO DE BELCHITE
\end{abstract}

Josep M. Mata-Perelló

Aquest recorregut va ésser experimentat amb docents el dia 1 DE MAIG DEL 2010 


\section{RECORRIDO DESDE AZUARA A LETUX, ALMONACID DE LA CUBA, BELCHITE Y AL PLANERÓN, A TRAVÉS DEL PATRIMONIO GEOLÓGICO Y MINERO DE LAS COMARCA DEL CAMPO DE BELCHITE}

Por Josep M. Mata - Perelló

\section{ADVERTENCIAS PREVIAS}

Como en otros recorridos de RECONOCIMIENTO GEOLÓGICO (o de RECONOCIMIENTO GEOLÓGICO Y MINERO), el recorrido se compondrá de diversas PARADAS. En este caso serán seis.

Por otra parte, habrá que tener en cuenta, en todo momento, especialmente antes de empezar los recorridos de los diferentes tramos, el estado de los caminos y carreteras, por donde transitará el recorrido. Al respecto, cabe decir que prácticamente todos estos tramos se halla en buenas condiciones.

Finalmente, como ya hacemos en otros recorridos similares, queremos decir que hace falta tener un cuidado muy especial en el respeto a la naturaleza, a lo largo de todo el recorrido del itinerario, y también fuera de él.

\section{BREVE INTRODUCCIÓN GEOLÓGICA}

El recorrido de este itinerario, se desarrollará exclusivamente por una de las tres unidades geológicas que constituyen el suelo y el subsuelo de Aragón. Concretamente por la Depresión Geológica del Ebro (en donde se iniciarla y finalizara el recorrido del itinerario).

Así, a lo largo de todo de todo el recorrido del itinerario, se irán encontrando afloramientos cenozoicos, en su mayoría de carácter arcilloso y calcolutítico, pertenecientes al Mioceno. De entre estos materiales, cabe destacar los afloramientos carbonatados y los yesosos, explotados en diversos lugares del recorrido. Asimismo, a menudo, encontraremos afloramientos de los materiales detríticos cuaternarios, por encima de los anteriores

\section{BREVE INTRODUCCIÓN GEOGRÁFICA}

El recorrido del presente itinerario se efectuará exclusivamente por una comarca aragonesa, la del Campo de Belchite. Así, se iniciará en la población de Azuara, para terminar en las cercanías de Codo, entre esta población y la de Quinto. 
En este recorrido, se circulará por los términos municipales de: Azuara, Letux, Almonacid de la Cuba, Belchite y Codo, todos ellos de la comarca del Campo de Belchite.

\section{OBJETIVOS GENERALES DE ESTE ITINERARIO}

En este itinerario, los objetivos generales que se han de conseguir, se pueden concretar en los siguientes aspectos:

1.- Estudio y reconocimiento de los materiales cenozoicos (en buena parte del Mioceno) situados en la Depresión Geológica del Ebro, que iremos encontrando a lo largo del recorrido del itinerario, entre las inmediaciones de la población de Azuara y las de Codo.

2.- Visión de algunas de las antiguas explotaciones encontradas a lo largo del recorrido del itinerario. En concreto de:

2A) de alguna de las explotaciones de gravas, que encontraremos en las cercanías de Letux, entre los afloramientos de las terrazas del río Aguasvivas.

2B) de diversas explotaciones de yeso, situadas fundamentalmente en el municipio de Almonacid de la Cuba.

2C) de diversas explotaciones de calizas, concretamente de las antiguas explotaciones del Mojón Alto, en las cercanías de Belchite, inactivas.

2D) de algunas de las explotaciones de lutitas y calcolutitas que encontraremos en Valforné, en el municipio de Belchite.

3.- Observación del impacto producido por las actividades mineras. I si se da el caso, de las restauraciones realizadas para paliar este impacto.

4.- Visión de los diferentes lugares directamente relacionados con el Patrimonio Geológico y Minero que iremos encontrando a lo largo del recorrido del presente itinerario. Así en relación con el Patrimonio Geológico veremos los Cantiles del río Cámaras y el Planerón. Y en relación con el Patrimonio Minero veremos algunos hornos de yeso en las cercanías de Almonacid de la Cuba.

\section{ANTECEDENTES BIBLIOGRÁFICOS}

En relación con este itinerario, no conocemos ningún antecedente, relativo a otro itinerario que discurra por este lugar. En este sentido, este itinerario constituye un antecedente, si no estamos equivocados.

Por otra parte, haremos mención de algunos trabajos, de carácter geológico generalista, que corresponden a los trabajos del IGME (1972, 1974 y 1975), relativos al Mapa Geológico de España (a Escala 1.200.000), al Mapa Metalogenético de España y al Mapa de Rocas Industriales de España 
Con respecto a las mineralizaciones que iremos encontrando, mencionaremos los trabajos de: CALVO (2001), CALVO et altri (1988); MAESTRE (1845); así como nuestros trabajos: MATA-PERELLÓ (1987 y 1998).

También mencionaremos el trabajo de PRAMES (2005) dedicado a la comarca del Campo de Belchite. Así como el del GOBIERNO DE ARAGÓN (2001), dedicado a los Puntos de Interés Geológico de Aragón.

Finalmente, diremos que todos estos trabajos (así como otros que ahora no hemos aludido), figurarán mencionados, por orden alfabético, en el apartado dedicado a las REFERENCIAS BIBLIOGRÁFICAS.

\section{RECORRIDO DEL ITINERARIO}

Este recorrido se iniciará en las inmediaciones del pueblo de Azuara, en donde se realizará la primera parada. Tras ello, el recorrido se desplazará a Letux, en donde se efectuará otra parada. Seguidamente, el recorrido continuará hasta las inmediaciones de Almonacid de la Cuba, en donde se efectuará una parada antes de llegar. Y otra yendo hacía Belchite, en el municipio de este último pueblo. A continuación, tras llegar a Belchite, el recorrido continuará hacia el Este, yendo a Codo, en donde no se hará ninguna parada. Tras ello se se efectuaran dos paradas más, en el término municipal de Belchite: una en el Planerón y otra en Valforné, terminando el recorrido del itinerario.

\section{DESCRIPCIÓN DEL ITINERARIO}

Como de costumbre, haremos una serio de PARADAS (o ESTACIONES), en donde se realizaran diversas explicaciones en torno a las características del lugar en donde se halla la PARADA. Por otra parte, en ellas haremos mención del término municipal dónde se encuentran, así como del número del "Mapa Topográfico Nacional (a escala 1:50.000, que indicaremos entre paréntesis. Así, ahora (en este recorrido) utilizaremos solamente tres hojas: concretamente la $\mathbf{4 1 2}$ (o de Pina de Ebro), 439 (o de Azuara) y la 440 (o de Belchite). Así, la relación ordenada de las paradas que constituyen el recorrido de este itinerario, es la siguiente:

PARADA 1. CANTILES DEL RÍO CÁMARAS, (término municipal del Azuara, comarca del Campo de Belchite). (Hoja 439).

El recorrido cabrá iniciarlo en este lugar, a unos $6 \mathrm{Km}$ de Azuara, hacía el poniente, en la carretera que conduce a Herrera de los Navarros, concretamente frente a los Cantiles del río Cámaras.

En este lugar, situado en la Depresión Geológica del Ebro podemos ver los Cantiles del río Cámaras, formados a partir de la erosión del mencionado río, sobre masas de conglomerados cenozoicos del Mioceno. 


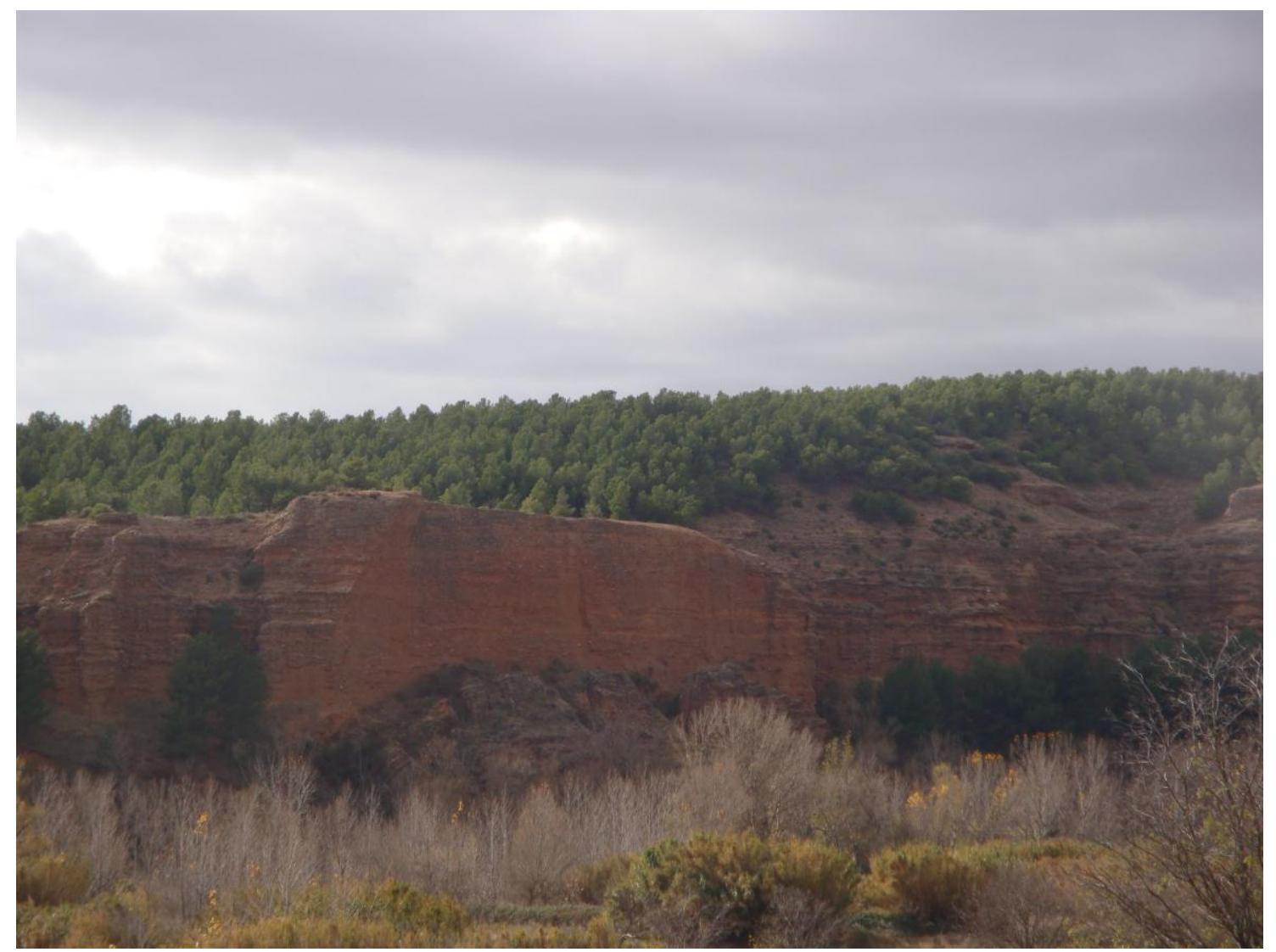

CANTILES DEL RÍO CÁMARAS

PARADA 2. GRAVERA DE LETUX, (término municipal de Letux, comarca del Campo de Belchite). (Hoja 440).

Después de realizar la parada anterior, conviene efectuar un recorrido hasta el cercano pueblo de la Azuara. Luego, desde ahí nos convendrá seguir hasta Letux. Al llegar ahí, iremos hasta una cercana gravera. Se encuentra saliendo del pueblo hacia Belchite, a menos de 0`7 Km del núcleo de la población. Así, desde la parada anterior, habremos realizado un recorrido muy cercano a los $13-14 \mathrm{Km}$, para llegar hasta donde ahora estamos.

En este recorrido, hemos ido transitando en todo momento por la Depresión Geológica del Ebro, en donde ahora nos encontramos situados. En este sector, la depresión se halla colmatada por sedimentos cenozoicos del Mioceno, aunque muy a menudo recubiertos por terrenos terrígenos del cuaternario.

Precisamente, en este sector nos encontramos frente a un afloramiento de los materiales terrígenos del cuaternario. Estos forman parte de la terraza del río Aguasvivas, que discurre junto a Letux.

En este lugar, estos materiales han sido explotados en una antigua gravera, actualmente abandonada. 


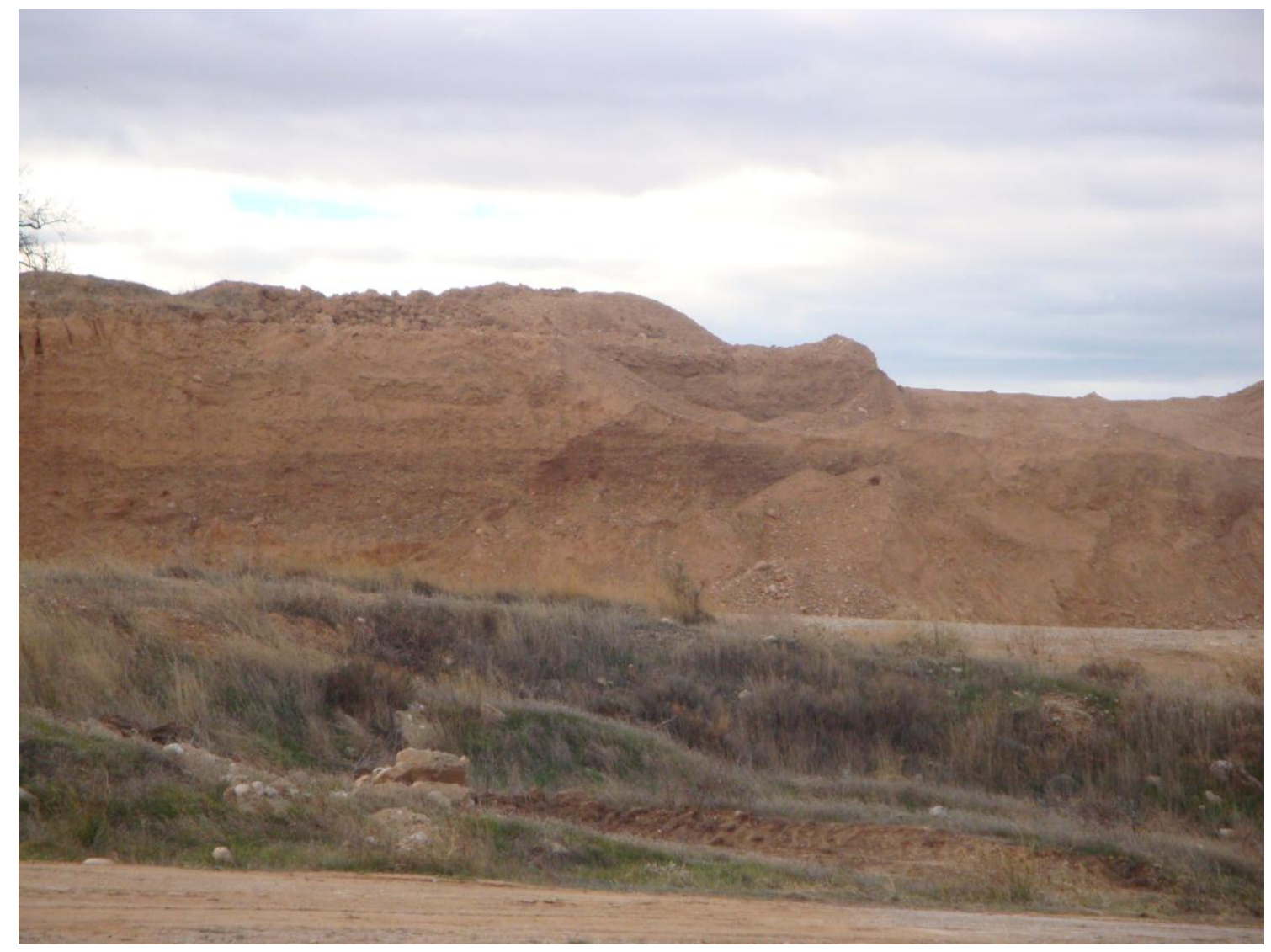

UN ASPECTO DE LA GRAVERA DE LETUX

PARADA 3. HORNOS DE YESO DE ALMONACID DE LA CUBA, (término municipal de Almonacid de la Cuba, comarca del Campo de Belchite). (Hoja 440).

Tras realizar la parada anterior, conviene continuar hacía Belchite por la carretera que hemos tomado en Azuara. A menos de 1'5 - 1'8 Km de la parada anterior, llegaremos al paraje de las Canteras. En este paraje, perteneciente al municipio de Almonacid de la Cuba, efectuaremos una nueva parada, dentro de este recorrido.

Como en los casos anteriores, todo este trayecto lo habremos realizado dentro de la Depresión Geológica del Ebro. Así habremos encontrado ahora afloramientos de los materiales yesosos que la colmatan.

Precisamente aquí, estos niveles de yesón han estado explotados en diversas canteras (yeseras). Asimismo, los materiales extraídos han estado tratados en diversos hornos de yeso.

Este importante conjunto de hornos, forma parte de nuestro Patrimonio Minero, a pesar de que algunos no se hallan en buen estado de conservación. 


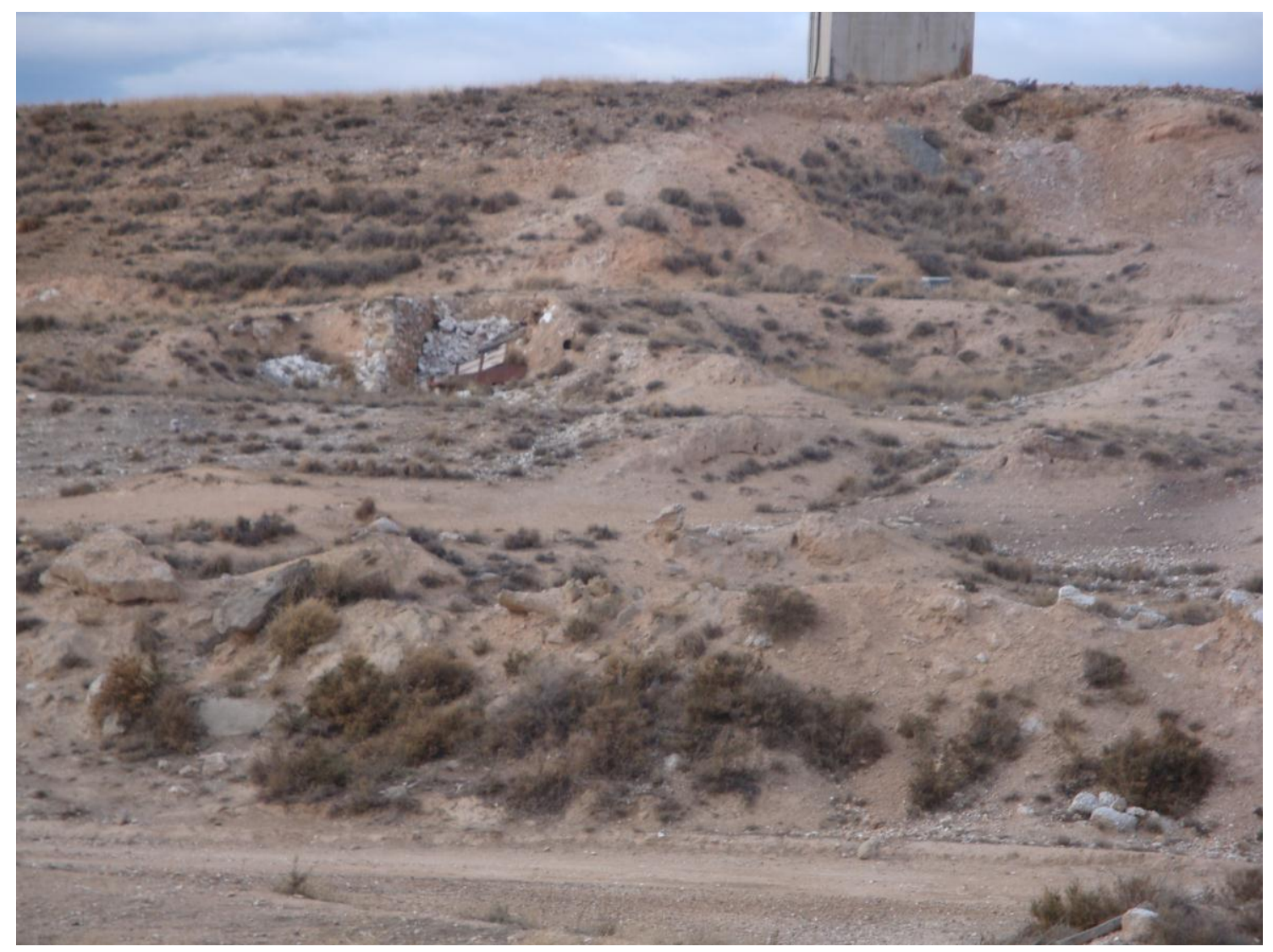

DOS DE LOS HORNOS, A MEDIA MONTAÑA

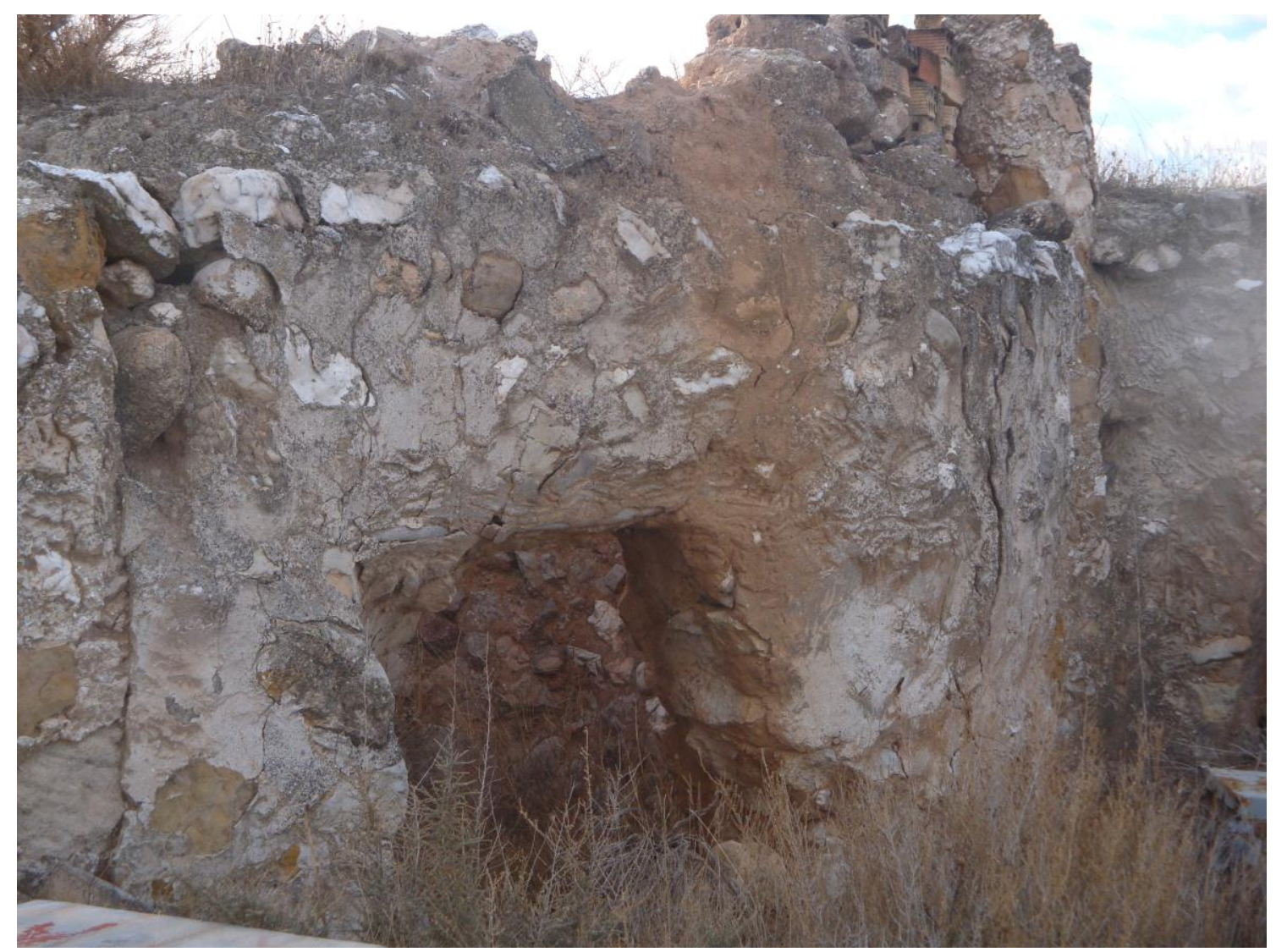

OTRO DE LOS HORNOS 
PARADA 4. CANTERAS DEL MOJÓN ALTO, (término municipal de Belchite, comarca del Campo de Belchite). (Hoja 440).

Después de realizar la parada anterior, conviene continuar por la carretera, yendo ahora hacía la población de Belchite. Sin embargo, a unos $2 \mathrm{Km}$ de la parada anterior, encontraremos una serie de antiguas explotaciones de calizas, en donde realizaremos una nueva parada.

En este recorrido habremos discurrido de nuevo por la Depresión Geológica del Ebro, entre afloramientos de los materiales miocénicos y de los cuaternarios que la colmatan. Así, en este lugar se hacen patentes unos afloramientos de materiales calcáreos del Mioceno. Estos materiales han sido explotados en distintas canteras situadas en este sector, aunque en estos momentos están todas ellas paradas, al igual que otras canteras de áridos situados en esa zona.

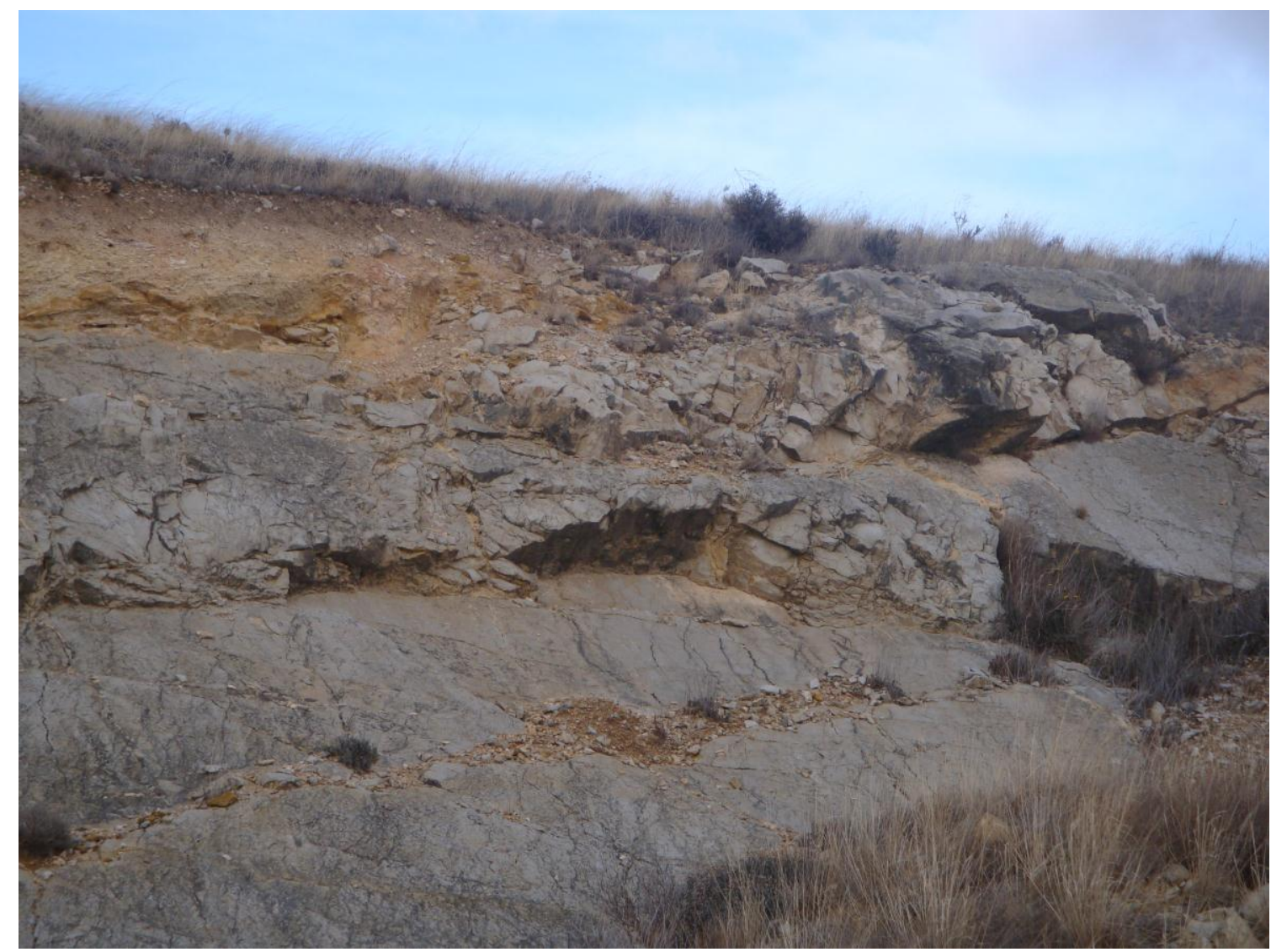

UNA DE LAS ANTIGUAS EXPLOTACIONES DE MATERIALES CALCÁREOS

PARADA 5. EL PLANERÓN, (término municipal de Belchite, comarca del Campo de Belchite). (Hoja 412).

Después de realizar la parada anterior, conviene seguir por la carretera que conduce a Belchite. Luego, tras sobrepasar la población nos convendrá seguir hacia el levante, yendo hacía Codo. Tras sobrepasar la población, nos convendrá seguir hacia 
Quinto, hasta encontrar por la izquierda el camino que se dirige al Planerón. Nos convendrá tomarlo, para hacer ahí una nueva parada, a unos $10 \mathrm{Km}$ de la anterior.

En este recorrido, hemos encontrado (una vez más) los materiales cenozoicos y los cuaternarios que rellenan la Depresión Geológica del Ebro, en donde nos encontramos desde el inicio del recorrido.

En este lugar hay una interesante zona endorreica (el Planerón). Ahí se ha desarrollado una laguna y un interesante patrimonio natural (geológico, florístico y faunística).

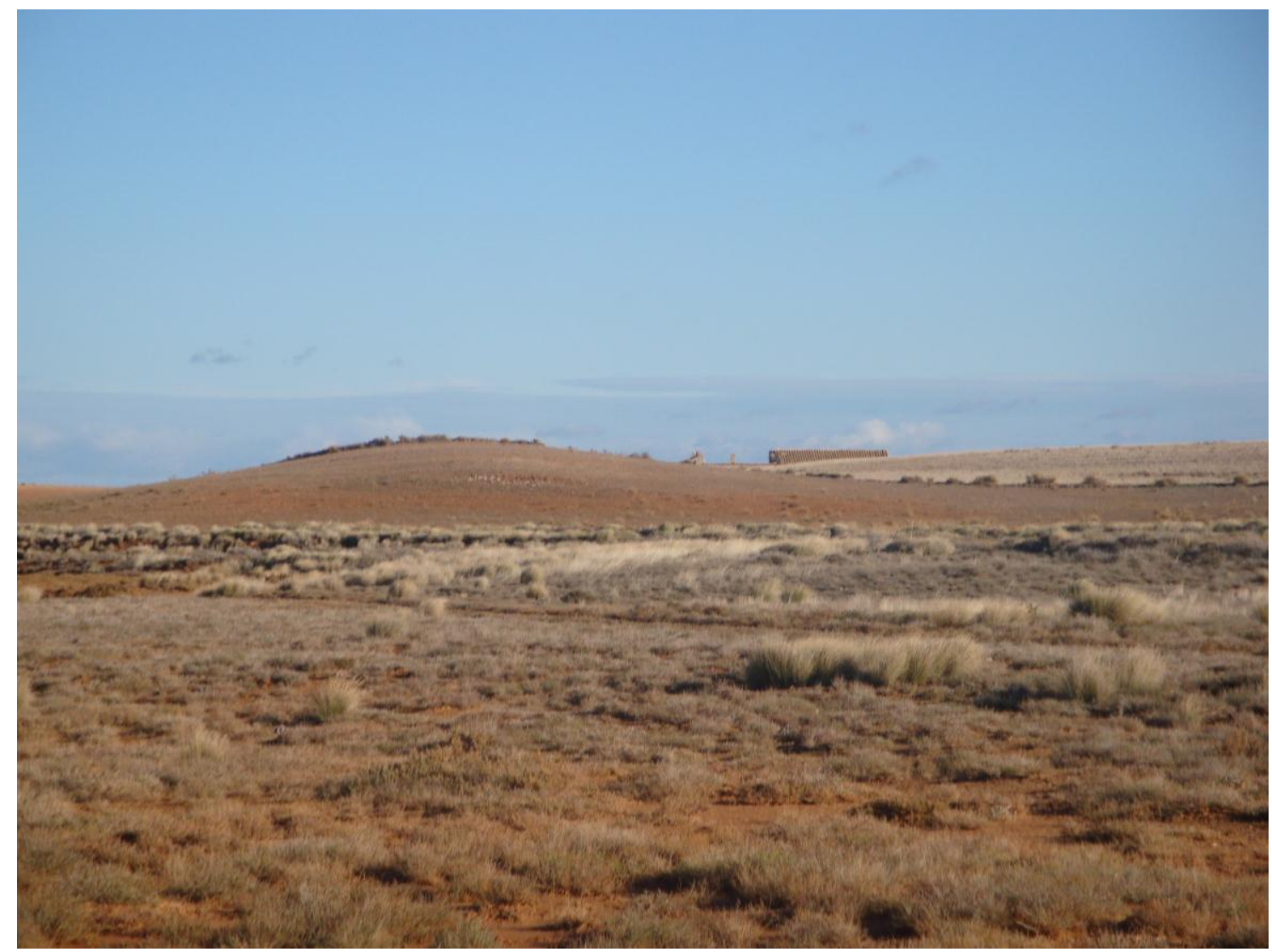

EL PLANERÓN

PARADA 6. ARCILLERAS DE VALFORNÉS, (término municipal de Belchite, comarca del Campo de Belchite). (Hoja 412).

Después de realizar la parada anterior, conviene retornar a la carretera que se dirige hacia Quinto. Sin embargo, pronto encontraremos un camino que dirige (por la derecha) hacía las explotaciones arcillosas de Valfornés. Ahí efectuaremos la última parada de este itinerario, a unos $6 \mathrm{Km}$ de la parada anterior, pero aún dentro del término municipal de Belchite.

En este recorrido habremos ido encontrando afloramientos de los materiales cenozoicos que rellenan la Depresión Geológica del Ebro, en donde continuamos situados desde el inicio del itinerario. 
Estos materiales son los que afloran en el lugar de la parada. Se trata de niveles arcillosos y margosos explotados en este lugar. Sin embargo, todas las explotaciones están actualmente cerradas.

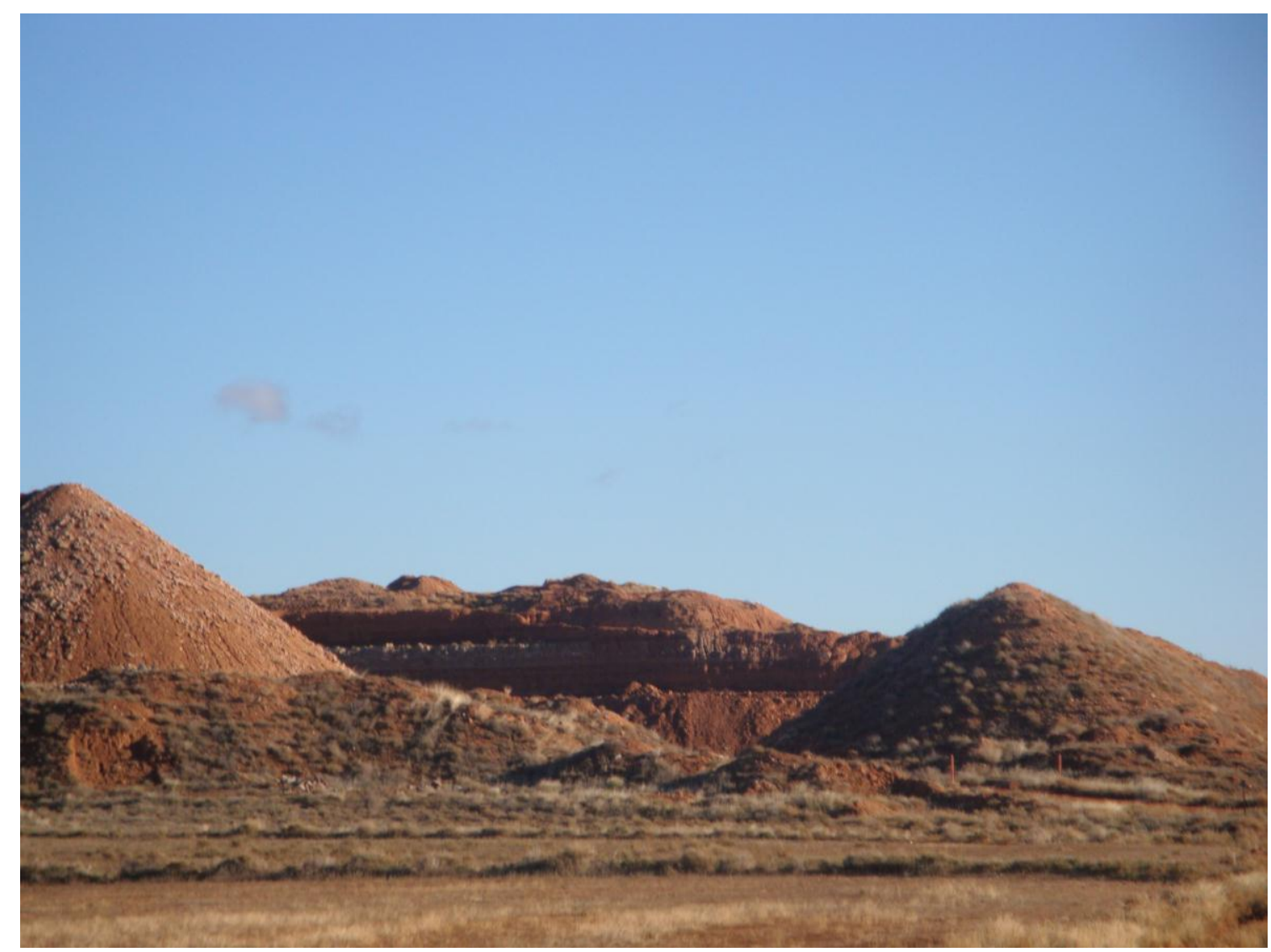

EXPLOTACIONES DE VALFORNÉ

\section{EN ESTE LUGAR FINALIZA EL ITINERARIO}

\section{BIBLIOGRAFÍA}

CALVO, M. (2001).- Las Minas de Sal de Remolinos, Zaragoza. Revista de Minerales, Vol. 2, no 2, pp. 3 - 22. Barcelona

CALVO, M. et altri (1988). - Minerales de Aragón, Colección Temas Geológicos, 207 Pág. Zaragoza

GOBIERNO DE ARAGÓN (2001).- Puntos de Interés Geológico de Aragón. Consejería de Medio Ambiente del Gobierno de Aragón. Zaragoza

IGME (1972).- Mapa Geológico de España a escala 1:200.000 (Síntesis de la cartografía existente). Hoja y Memoria nº 32 (Zaragoza). Inst. Geol. Min. España 
IGME (1973).- Mapa Metalogenético de España a escala 1:200.000. Hoja y Memoria $n^{\circ} .32$ (Zaragoza). Inst. Geol. Min. España

IGME (1975).- Mapa de Rocas Industriales de España a escala 1:200.000. Hoja y Memoria $n^{\circ} .32$ (Zaragoza). Inst. Geol. Min. España

MAESTRE, A. (1845).- Descripción geognóstica del Distrito Minero de Cataluña y Aragón. Anales de Minas, t. III. Madrid

MATA - PERELLÓ, J.; (1987).- Introducción al conocimiento de las mineralizaciones aragonesas. Mineralogistes de Catalunya, t.III, pp. 258-265. Barcelona

MATA - PERELLÓ, J.M. (1998).- Inventario Mineralógico de la comarca del Campo de Belchite, Rodeno, 25. 22 Pág. Manresa

PRAMES (2005).- Campo de Belchite. Colección RUTASCAL por Aragón. Prames, Gobierno de Aragón. 119 pag. Zaragoza. 